\title{
A importância de diferentes olhares (escuta ativa) na mediação familiar: a interdisciplinaridade
}

\section{The importance of different views (active listening) regarding family mediation: the interdisciplinarity}

\author{
Deborah Regina Lambach Ferreira da Costa é graduada em \\ Direito pela Universidade Federal do Paraná, mestre e doutora \\ em Direito Civil Comparado pela Pontifícia Universidade Católica \\ de São Paulo (PUC/SP), onde leciona Direito Civil desde 1992. \\ Ingressou na carreira de Procurador do Município de São Paulo \\ por meio de concurso público em 1989, nomeada para cargos \\ de assessoria jurídica em Secretaria, atuando como parecerista, \\ presidente de comissão de licitação, processo administrativo, \\ contencioso judicial e, ainda, nas comissões julgadoras de \\ prêmios relevantes à carreira.
}

Contato: deborahlambach@hotmail.com

\section{Resumo}

0 presente trabalho tem por finalidade debater a importância da mediação na solução dos conflitos sociais, em especial os familiares. Pretende-se discutir a viabilidade de se implantar, no nosso país, a chamada cultura da paz. 0 ponto central escolhido para dissertar a esse respeito foi o da comediação, em que a atuação conjunta de dois mediadores, de diferentes áreas de formação (advogados, psicólogos, pedagogos), com experiências de vida variadas, homens e mulheres com visões distintas, apresenta-se, ao nosso sentir, mais rica e profícua para a solução dos conflitos levados à mediação justamente pela troca de experiências dos envolvidos durante o processo. Outra vertente da discussão é a necessidade de capacitação de profissionais para atuar como mediadores, bem como as principais características que devem possuir, o papel a desempenhar e, principalmente, o empoderamento das partes para a tomada da decisão que acharem melhor. Nesse sentido, acreditamos que a mediação implementada na escola, como disciplina autônoma ou como 
atividade durante as aulas, contribuirá sobremaneira para a efetivação da paz social.

Palavras-chave: comediação, interdisciplinaridade, cultura da paz; escola.

\begin{abstract}
This paper aims to discuss the importance of mediation in settlement of a dispute, especially regarding family conflicts. One of the goals is to discuss the viability of implementing, in our country, the so called "culture of peace". The main purpose of this paper is to write about co-mediation, when two mediators work together, being from different backgrounds (lawyers, psychologists, pedagogues) with life experiences of all kinds, men and women, meaning the richest and the most successful way of solving conflicts, especially because of the exchanging of experiences during the process. It also wishes to discuss the need of training professionals to work as mediators; the principal skills they need to have; the roll they have to play as neutral facilitators and to guide the parties to reach an agreement. The conclusion is that mediation should be taught at school, as a subject or extra activity during classes, as peace-building toolbox.

Keywords: co-mediation,interdisciplinarity, culture of peace, school.
\end{abstract}

Os conflitos são inerentes às relações humanas. 0 convívio em sociedade impõe à pessoa direitos e deveres e, principalmente, a responsabilidade de coexistir, interagindo com as demais, em um ambiente saudável, de respeito mútuo.

Entretanto, quando surgem as diferenças, as relações estremecem e os conflitos que emergem muitas vezes não são solucionados pelos interlocutores.

Na busca de uma solução e diante da vedação da prática da justiça pelas próprias mãos (autotutela), os conflitos são submetidos ao crivo do Poder Judiciário, criticado pela morosidade, falta de recursos materiais e de servidores, alto custo e imposição (de cima para baixo) da decisão por um terceiro (Estadojuiz), potencializando a situação gerada pela falta de diálogo, principalmente nos conflitos familiares, havendo um maior desgaste dos relacionamentos já corroídos.

De forma que a solução imposta por um terceiro, no caso o juiz, sem a efetiva participação dos agentes em conflito (das 
partes litigantes), faz com que este tome uma dimensão maior, não resultando no verdadeiro objetivo que é o apaziguamento da relação conflituosa, com a restauração do vínculo outrora estabelecido entre esses agentes.

A "Justiça é obra coletiva", diz o Presidente do Tribunal de Justiça de São Paulo, Renato Nalini (2014), para quem, edificar uma cultura de pacificação não atende exclusivamente à política de reduzir a invencível carga de ações submetidas ao Judiciário.

É imprescindível, para o exercício da cidadania e da democracia, que os indivíduos enfrentem seus problemas e os resolvam com autonomia, sem a imposição de uma decisão judicial. Se assim fosse, na sociedade brasileira prevaleceria a "cultura da pacificação" e não a dominante "cultura da sentença".

Caetano Lagastra Neto (2002) frisa que o exemplo mais expressivo do procedimento de mediação vem das lições de Confúcio, na antiguidade chinesa, onde o conceito de moralidade contrapõe-se ao de legalidade, fixando-se na figura do shuofull - i.e., persuasão pelo diálogo -, pois apenas as pessoas despidas de bom senso dirigemse ao Judiciário. Assim, a negociação tem início pela intervenção de parentes, vizinhos, moradores do bairro, do inspetor de quarteirão etc., e só como último recurso busca-se o juiz ou o Judiciário.

Kazuo Watanabe foi um dos precursores das mudanças implementadas pela comunidade jurídica brasileira no sentido de promover uma verdadeira reforma do Poder Judiciário objetivando maior eficiência na prestação da Justiça (e não apenas na prestação jurisdicional). Criou o chamado modelo "multiportas", constituído de meios nãoadversariais de solução de conflitos. Procura-se, com a instituição dessa Política Pública, a solução adequada dos conflitos de interesses, com a participação decisiva das partes envolvidas, preservando o relacionamento das mesmas, propiciando a justiça coexistencial.

Assim, para operacionalizar a mudança de mentalidade dessa mesma comunidade jurídica (juízes, advogados, serventuários da justiça etc.), enraizada na cultura do litígio (do embate, do confronto), buscou-se alterar paradigmas, adotando-se os chamados meios alternativos - ou melhor - meios adequados de solução das controvérsias (MASCS): conciliação, mediação, negociação e arbitragem. Esse novo paradigma tira de cena - do papel de protagonista - o juiz, outorgando às partes envolvidas no conflito ou até mesmo a um terceiro (no caso da arbitragem) a missão de solucioná-lo. 
0 deslinde da controvérsia não é mais imposto pelo magistrado após um longo, exaustivo e desgastante processo judicial, em que as partes saem mais machucas do que quando iniciaram o processo. A sentença, outrora adjudicada às partes, resultando em um "ganhaxperde", é "substituída" por uma decisão dos próprios envolvidos. Ou seja, esse novo paradigma resgata princípios constitucionais adormecidos, em especial, o da dignidade da pessoa humana, o da cidadania e o da paz social.

Fala-se em um "ganhaxganha", uma vez que as partes constroem o comum; as partes são coconstrutoras de suas realidades.

Na mediação, a solução do conflito é encontrada pelas partes envolvidas, sendo o mediador "um facilitador dos problemas". Ele vai tratar da relação jurídica, fazendo com que as partes cheguem a um consenso por meio da negociação por princípios.

De modo que o trabalho do mediador familiar, por exemplo, objetiva um diálogo franco entre casais e filhos em situação conflituosa, conduzindo-os à tomada de decisão com autonomia, propiciando o convívio paterno-materno-filial, restaurando (ou resgatando) o vínculo de respeito e afetividade familiar.

A ministra Nancy Andrighi (2011) denomina de "Justiça doce" a solução dos conflitos pelos meios nãoadversariais. Isso porque as partes envolvidas no conflito se "empoderam" e tomam a decisão que Ihes parece mais justa, encerrando o conflito sem que haja a imposição de uma decisão tomada por um terceiro: o juiz.

O objetivo da mediação, ressalta Corina Schabbel (2013), é a manutenção das relações sociais e o exercício da responsabilidade, alçando a mediação ao patamar da chamada "terceira onda" do movimento de acesso à justiça, democratizando a sociedade, já que ao "empoderar" o cidadão na solução do conflito, passa a coexistir as figuras do cidadão participante e do cidadão protegido, dando à mediação características predominantemente reformistas e de transformação para melhor.

Fixada essa premissa, surge a figura do mediador como terceiro "facilitador" da busca da solução do conflito que, independentemente da formação técnica, seja de advogado, psicólogo, psiquiatra, assistente social ou pedagogo, é um humanista, devendo pautar a sua conduta nos princípios da confidencialidade, da decisão informada, da competência, do empoderamento das partes (estimulando-as a resolver o 
conflito e os conflitos futuros em função de justiça vivenciada na autocomposição) e da validação da decisão por elas tomadas (conscientizando-as de que são seres humanos merecedores de atenção e respeito), agindo com imparcialidade, independência e autonomia, respeitando à ordem pública e às leis vigentes.

Mas para tanto, há que se capacitar os profissionais que entram nesse novo cenário. Para isso, foram criados os Centros Judiciários de Solução de Conflitos e Cidadania e os Núcleos Permanentes de Métodos Consensuais de Solução de Conflitos. Com eles, mesmo que as partes tenham iniciado o embate por meio do processo judicial, é sempre aberta a via da conciliação. 0 ideal, é claro, é que se procure esses centros, promovidos e regulamentados pela Resolução 125/2010 do CNJ que traça diretrizes - ainda que básicas - para a implementação dessa nova mentalidade: a cultura da paz.

Assim, para que haja efetividade na implementação dessa nova mentalidade, há que se instrumentalizar o mediador. Há que dotálo de mecanismos para evitar o maior obstáculo que é a falha na comunicação: quando um dos comunicadores não possui a mesma quantidade de informação que o outro.

0 mediador tem como norte focar os problemas trazidos à discussão (e não as pessoas envolvidas no litígio). 0 mediador deve fazer as pessoas reagirem às ideias, e não reagirem umas às outras, o que, na verdade, acirra o conflito.

De modo que a comunicação é papel de extrema relevância para o sucesso da solução pacífica dos conflitos trazidos ao mediador. Isso porque a função deste é conduzir as partes ao seu "empoderamento", direcionando-as ao reconhecimento dos interesses do outro, num ambiente propício, valendo-se de artifícios como discussão em mesa redonda ou em círculo (evitando a preponderância de posições).

A comunicação verbal, a não verbal (gestos) e a para-verbal (sons) são instrumentos que devem ser explorados pelo mediador: uma escuta sensível do mediador é necessária para restabelecer a comunicação entre as partes, buscando o diálogo: cada parte envolvida tem a sua vez de falar.

0 mediador deve ter uma função investigativa, saber quais os reais motivos que subjazemo conflito, formulando perguntas e mais perguntas com a finalidade de que estes aflorem de cada uma das partes envolvidas. Enfim, conduzir o diálogo para que as próprias partes encontrem a solução que melhor lhes satisfaz. 
0 mediador deve ter capacitação para lidar com o conflito, exigindo-se dele, sobretudo, o conhecimento de si próprio, concentração, sensibilidade, humanidade, agindo de modo a se colocar no lugar do outro, construindo um elo de confiança com as partes em conflito, buscando, enfim, a empatia. 0 mediador deve ser capaz de administrar relações interpessoais.

As características acima se sobrepõem às qualidades ou capacidades profissionais de advogado, psicólogo, psiquiatra etc. Isso porque o mediador deve ter, como ressaltado, uma formação humanista e aprofundar-se no conhecimento do conflito: sua origem, seu desdobramento, sua dimensão.

Deve empenhar-se a restaurar o canal de comunicação entre as partes, abrindo um leque de possibilidade, de soluções, "empoderando" os agentes para que, voluntariamente, com autonomia, enfrentem a situação conflituosa.

A ideia domediador, como terceiro facilitador, pode ser resumidana frase de Francis Bacon, para quem "o homem deve criar oportunidades e não somente encontrá-las". Nessa situação, a oportunidade criada não é apenas de solução do conflito, mas de restauração do vínculo.

Nessa toada, pode-se afirmar com segurança que a interdisciplinaridade na mediação é imprescindível, sobretudo nos conflitos de família. No processo de mediação, o papel de mediador pode ser assumido por uma ou mais pessoas, trabalhando em conjunto, em equipe multiprofissional, o que torna o trabalho mais qualificado.

Quando no conflito surgem questões que envolvem os filhos (guarda, alimentos etc.), o trabalho da comediação, com profissionais de diferentes áreas, (por exemplo, direito e pedagogia, ou direito e psicologia), atuando em equipe, com conhecimentos multidisciplinares, faz emergir no processo de mediação um leque de possibilidades, permitindo ao casal a tomada de decisões em conjunto.

0 trabalho conjunto é mais rico no sentido das diversas experiências dos comediadores - não necessariamente oriundas de seu campo de expertise - pois há um compartilhamento de conhecimentos, possibilitando que uma das partes tenha mais empatia, confiança emum do que no outro e vice-versa. Os comediadores se complementam, pois do processo conjunto surgem mais opções e ideias. 
Ademais, o trabalho de mediação exige um elevado grau de concentração, havendo muita informação para que o mediador assimile em que medidaa atuação em equipe traz uma saudável divisão de responsabilidades.

Segundo Valeria Lagastra Luchiari (2013), a capacitação do mediador é tarefa que vem sendo enfrentada no Brasil ainda a passos tímidos, importando-se a metodologia de várias escolas de mediação, sem contudo se ter desenvolvido um modelo nacional, tão necessário.

Tome-se o exemplo do país vizinho, a Argentina, onde se implementou um Programa Nacional de Mediação que abrange vários setores da sociedade (escolas, empresas, universidades), inclusive, com obrigatoriedade, desde 1995, da mediação prévia à interposição da ação judicial.

A trajetória moderna aponta a tendência da inclusão da matéria no currículo das escolas de ensino fundamental e nos cursos superiores do Brasil, tão defendida por Nancy Andrighi, para quem o magistrado não deve se contentar com o papel de aplicador da lei. "Tem de ser um homem de espírito altruísta. É proibido passar a vida sem se preocupar com o destinatário das decisões e com as consequências da ordem judicial. É proibido envelhecer, desistir dos novos desafios da vida que se apresentam a todo instante" (ANDRIGHI, 2011, p. 4). Ela propõe, para que haja maior cumplicidade entre escola e família, a inclusão da mediação na grade escolar. Ressalta a ministra que "a mediação é uma forma de diluir conflitos e não de resolvê-los. A diferença fundamental entre um e outro é que, no primeiro caso, os conflitos são apagados para sempre" (ANDRIGHI, 2011, p. 4).

\section{REFERÊNCIAS}

ANDRIGHI, Nancy. Acordo no lugar de litígios, Boletim ENFAM, n. 12, out./dez. 2011.

DINIZ, Maria Helena. Curso de Direito Civil. 26 ed. São

Paulo:Saraiva, 2011.

LAGASTRA NETO, Caetano. Mediação e Direito de Família. $R$. CEJ, Brasília, n. 17, p. 111-116, abr./jun. 2002. 
LUCHIARI, Valeria Lagastra. Desafio de Capacitar

Conciliadores e Mediadores, Revista Científica Virtual da ESA, n. 13, p. 14-20, verão de 2013.

NALINI, Renato. Justiça é obra coletiva. Folha de São Paulo, 9 mar. 2014.

SCHABBEL, Corina. Mediação em Tempos de Mudança, Revista Científica Virtual da Escola Superior de Advocacia da $O A B$ - SP, v. 5, n. 13, verão 2013.

Recebido em: 26/02/2015

Revisto em: 27/04/2015

Aprovado em: 30/04/2015 